\title{
BODY MASS INDEX IN PATIENTS WITH POLYCYSTIC OVARIAN SYNDROME AND ITS RELATION TO DOSE AND DURATION OF HMG, OVULATION RATE AND PREGNANCY RATE
}

\author{
By \\ Abdallah G. Mohammad, Ismail T. El-Garhy, Noha M. Sabry \\ Department of Obstetrics and Gynecology, Faculty of Medicine, Al -Azhar University \\ Corresponding author: Abdallah G. Mohammad, \\ E-mail: elansaryabdo88@gmail.com
}

\begin{abstract}
Background: Polycystic ovary syndrome (PCOS) is one of the most common causes of endocrinological disorders affecting $5-10 \%$ of women in reproductive age. It is the most important cause of anovulation and infertility.

Objective: To examine the relation of body mass index in PCOS patients with dose and duration of Human Menopausal Gonadotropin (HMG), ovulation rate and pregnancy rate.

Patients and Methods: The study was retrospectively conducted on 150 women selected from patients attending the infertility clinic of Al-Azhar hospitals, Faculty of Medicine, Al-Azhar University during the period from August 2018 till July 2020, and we revised and collected that data from the records. All cases were selected after fulfilling inclusion and exclusion criteria. The patients were divided into three equal groups according to their body mass index, Group A: patients with normal body mass index (BMI 19-24.9), Group B: patients with overweight (BMI 25-29.9) and group C: patients with obesity (BMI equals or more than 30).

Results: There was a statistical significance as regards pregnancy rates between studied groups. In the current study there was a statistical significant difference between three groups as regards the mean age. There was no statistical significant difference between three groups as regards the mean Follicular Stimulating Hormone (FSH), Luteinizing Hormone (LH), Estradiol (E2), Prolactin (PRL) and Thyroid stimulating Hormone (TSH). According to the days of stimulation, group C showed a significant increase than group A and B. The dose of HMG used in the three studied groups, showed a significantly higher dose used in group C than group A and B. The ovulation rate was $68 \%$ in group A, 56\% in group B and $28 \%$ in group C. The results were compared with other studies of similar scope and most of them were recent ones. In our study, obesity had negative impact on ovulatory functions. It seemed that obesity was a negative prognostic factor for women referred to vitro fertilization (IVF) treatment. They should be encouraged to change lifestyle habits in order to lose weight before starting fertility treatment. Although our findings did not support a policy of excluding obese and overweight women from IVF treatment on the grounds of likely failure of ovulation induction or IVF, Beyond the IVF results, obesity increased morbidity for both mother and fetus. There was an increased risk in pregnancy hypertension, toxemia, gestational diabetes, Cesarean section, increased hospitalization, and the risk to their offspring of their abnormality in BMI.
\end{abstract}

Conclusion: Programs of weight loss are recommended for obese women undergoing in vitro fertilization, and the institution of a process of weight loss where appropriate, HMG can be given to patients with PCO adjusting dose according to their BMI and response with expecting satisfactory ovulation, and pregnancy rate.

Key words: Body mass index, polycystic ovarian syndrome, dose/duration, HMG, ovulation rate, pregnancy rate. 


\section{INTRODUCTION}

According to the data from the Global Database on Body Mass Index. There are wide variations in the prevalence of obesity throughout the world, ranging from India, where $1 \%$ or less of the population is obese, to the Pacific Islands, where the prevalence of obesity can reach up to $80 \%$ in some regions Obesity is thought to be result from a combination of environmental and genetic factors (WHO, 2015).

Obesity affects fertility through the presence of functional hyperandrogenism and hyperinsulinemia which accompanies coexisting insulin resistant state, leading to androgen excess and increase free androgen availability, alterations of granulosa cell functions and follicular development (Practice Committee of the American Society for Reproductive Medicine, 2013), (Dă̆ and Dilbaz B., 2017). PCOS is one of the most common causes of infertility due to anovulation in woman. The clinical features of PCOS are heterogeneous and may change throughout the lifespan, starting from adolescence to post- menopausal age (Bellver et al., 2018).

These affects ovarian steroidogenesis and decrease sex hormone binding globulin (SHBG) concentrations. Obesity also favors resistance to clomiphene citrate and gonadotropins induced ovulation and reduce outcomes of IVF/ ICSI cycles. Weight reduction in PCOS women using the therapeutic dose of insulin- sensitizing agents such as metphormin, diazoxide, troglitazone results in decrease of hyperinsulinaemia and hyperandrogenism (DiamantiKandarakis et al., 2012).
The value of weight loss to the infertile obese patients has been repeatedly shown in many studies; weight loss improves the chances of spontaneous or stimulated ovulation and facilitates interventions including laparoscopy and transvaginal scanning (Dă̆ and Dilbaz, 2015).

Polycystic ovary syndrome (PCOS) is a common disorder of chronically abnormal ovarian function and hyperandrogenism affecting $5-10 \%$ of the female population of reproductive age. It is a heterogeneous disorder characterized by menstrual irregularities, clinical and/or biochemical hyperandrogenism and hyperinsulinemia secondary to reduced insulin sensitivity (Susan et al., 2014).

In fact, over one-third to one-half of PCOS subjects are overweight or obese (Erin et al., 2014).

Obesity has been reported to affect Controlled Ovarian Hyperstimulation $(\mathrm{COH})$ in women undergoing treatment. Reported effects include prolonged $\mathrm{COH}$, increased dose requirement of gonadotrophin, increased incidence of follicular asynchrony and increasing cancelled cycles. All this leads to a smaller percentage of clinical pregnancies and a lower percentage of births (Sarais et al., 2016).

The present work aimed to examine the relation of body mass index in Patients with polycystic ovarian syndrome and its relation to dose and duration of human menopausal gonadotropin, ovulation rate and pregnancy rate

\section{PATIENTS AND METHODS}

This was a retrospective observational study that included 150 PCOS patients 
attended the infertility outpatient clinic of Obstetrics and Gynecology Department, Al-Azhar Hospitals, Faculty of Medicine, Al-Azhar University in the past two years. Data were collected in a period from August 2018 to July2020.

The study included patients with ages between 20-35 years, infertility more than one year diagnosed as having PCOS using the Rotterdam PCO diagnostic criteria (2 of 3 criteria): (a) Oligo- or anovulation: clinically diagnosed as oligo-/amenorrhea, i.e., menstrual cycles longer than 35 days or less than 10 menstruations per year. (b) Clinical and/or biochemical signs of hyperandrogenism, or (c) Polycystic ovaries: 12 or more follicles in an ovary, with each follicle measuring 2-9 $\mathrm{mm}$ in diameter and/or ovarian volume more than $10 \mathrm{ml}$.

Patients with any other cause of infertility other than PCO, other pathologies that results in PCO phenotype were excluded from the study.

Patients were divided into three equal groups (according to their body mass index): Group A: Women with PCOS and normal body mass index (BMI less than 19-24.99), Group B: Women with PCOS and overweight (BMI 25-29.9), and Group C: Women with PCOS $(n=50)$ with obesity (BMI equals or more than 30).

The three groups were evaluated regarding age, body mass index (BMI), biochemical criteria, number of induction days by HMG, ovulation rate after treatment and pregnancy rate.

All cases with the above criteria were recruited from the infertility outpatient clinic files as regarding.
General examination was revised to exclude any endocrinological abnormalities. BMI was calculated using the formula: weight in kilograms / height in meters squared. Check for the presence of hirsutism and galactorrhea. Abdominal examination was revised to exclude any abdominal or pelvi-abdominal masses.

Pelvic examination was revised to exclude any pelvic pathology.

Transvaginal ultrasound reports \& images were revised to confirm the presence of PCO ovarian morphology and to exclude any abnormalities.

Abdominal ultrasound was also revised to report the results of folliculometry after induction. B. hormonal profile was also revised to recover FSH, LH, TSH, PRL, $\mathrm{E} 2$, androgen and $\mathrm{FSH} / \mathrm{LH}$ ratio

All patients received HMG for induction of ovulation; HMG started day 3 of the cycle using $150 \mathrm{IU}, 1 \mathrm{st} \mathrm{U} / \mathrm{S}$ done 5 days later, the dose was adjusted accordingly. Then follow up with ultrasound was done every other day till one or more follicles reach $18-20 \mathrm{~mm}$. then HCG trigger of ovulation was given in a dose of 10000 IU. Timed intercourse was encouraged. Ovulation was confirmed with vaginal ultrasound. Ovulation rate and pregnancy rate (confirmed by U/S detection of gestational sac) was recorded. Successful Ovulation induction assessed by collapse of the dominant follicle, presence of fluid in Douglas pouch. Anovulation reported when no dominant follicle was achieved.

\section{Outcome measures:}

1. Dose and duration of HMG required reaching follicle size of $18-22 \mathrm{~mm}$. 
2. Ovulation rate confirmed by vaginal ultrasound (collapse of the dominant follicle, presence of fluid in the Douglas pouch).

3. Pregnancy rate confirmed by ultrasound (appearance of gestational sac by abdominal ultrasound).

\section{Statistical analysis}

Data were statistically described in terms of mean \pm standard deviation $( \pm S D)$, and range, or frequencies (number of cases) and percentages when appropriate. Comparison of numerical variables between the study groups was done using one way analysis of variance (ANOVA) test with post -hoc test comparisons. For comparing categorical data, Chi square ( $\chi 2)$ test was performed. Exact test was used instead when the expected frequency is less than 5. p values less than 0.05 was considered statistically significant. All statistical calculations were done using computer program SPSS (Statistical Package for the Social Sciences, SPSS Inc., Chicago, IL, USA) release 17 for Microsoft Windows (2006). The probability/significance value $\mathrm{P}$ value $<0.05$ was considered significant.

\section{RESULTS}

There was no statistical difference between the 3 groups regarding age, $\mathrm{FSH}$,
LH, TSH, E2 and PRL (P-Value > 0.05) (Table 1).

Table (1): Comparison between group $A$, group $B$ and group $C$ as regarding age and labs data

\begin{tabular}{|l|c|c|c|c|}
\hline $\begin{array}{l}\text { Groups } \\
\text { Parameters }\end{array}$ & $\begin{array}{c}\text { Group A } \\
(\mathbf{n}=50)\end{array}$ & $\begin{array}{c}\text { Group B } \\
(\mathbf{n}=50)\end{array}$ & $\begin{array}{c}\text { Group C } \\
(\mathbf{n}=50)\end{array}$ & P value \\
\hline $\begin{array}{l}\text { Age (year) } \\
\text { Mean } \pm \text { SD }\end{array}$ & $25.58 \pm 3.20$ & $25.74 \pm 3.00$ & $24.04 \pm 2.70$ & 0.080 \\
\hline $\begin{array}{l}\text { FSH } \\
\text { Mean } \pm \text { SD }\end{array}$ & $7.44 \pm 0.93$ & $7.44 \pm 0.89$ & $7.26 \pm 0.93$ & 0.538 \\
\hline $\begin{array}{l}\text { LH } \\
\text { Mean } \pm \text { SD }\end{array}$ & $9.18 \pm 1.00$ & $9.45 \pm 0.83$ & $9.12 \pm 1.04$ & 0.197 \\
\hline $\begin{array}{l}\text { SSH } \\
\text { Mean } \pm \text { SD }\end{array}$ & $1.92 \pm 0.64$ & $1.99 \pm 0.76$ & $2.00 \pm 0.70$ & 0.835 \\
\hline $\begin{array}{l}\text { PRL } \\
\text { Mean } \pm \text { SD }\end{array}$ & $8.01 \pm 1.89$ & $8.45 \pm 2.29$ & $9.96 \pm 2.65$ & 0.204 \\
\hline $\begin{array}{l}\text { E2 } \\
\text { Mean } \pm S D\end{array}$ & $38.33 \pm 8.30$ & $37.72 \pm 8.39$ & $38.36 \pm 6.14$ & 0.895 \\
\hline
\end{tabular}

That there was a statistical difference between the 3 groups regarding HMG (induction days),pregnancy rate and ovulation rate, the increase in BMI was positively correlated with HMG duration of induction (P-value < 0.05). BMI was inversely related to ovulation rate. where group A has ovulation rate higher than group B and group B has ovulation rate higher than group C. also BMI is inversely related to pregnancy rate where pregnancy rate was higher in group $A$ than $B$ and in group B than C (Table 2). 
Table (2): Comparison between group $A$, group $B$ and group $C$ as regarding ovulation, pregnancy and HMG

\begin{tabular}{|l|c|c|c|c|}
\hline Groups & $\begin{array}{c}\text { Group A } \\
(\mathbf{n = 5 0 )}\end{array}$ & $\begin{array}{c}\text { Group B } \\
(\mathbf{n = 5 0})\end{array}$ & $\begin{array}{c}\text { Group C } \\
(\mathbf{n = 5 0 )}\end{array}$ & P value \\
\hline Ovulation, no.(\%)\# & $34(68)$ & $28(56)$ & $14(28)$ & 0.001 \\
\hline Pregnancy, no.(\%)\# & $22(44)$ & $16(32)$ & $8(16)$ & 0.010 \\
\hline $\begin{array}{l}\text { HMG (induction days) } \% \\
\text { Mean+SD }\end{array}$ & $10.08 \pm 2.78$ & $12.40 \pm 2.98$ & $14.44 \pm 1.32$ & 0.001 \\
\hline
\end{tabular}

Using: \$One Way Analysis of Variance; \#Chi-square test; $\mathrm{p}$-value $<0.05 \mathrm{~S}$

Post HOC Test: Comparison between group A vs. group B ( $\mathrm{p}=0.001)$; Comparison between group A vs. group $\mathrm{C}(\mathrm{p}=0.001)$; Comparison between group $\mathrm{B}$ vs. group $\mathrm{C}(\mathrm{p}=0.001)$

Ovulation: Comparison between group A vs. group B ( $\mathrm{p}=0.303)$; Comparison between group A vs. group $\mathrm{C}$ $(\mathrm{p}=0.001)$; Comparison between group $\mathrm{B}$ vs. group $\mathrm{C}(\mathrm{p}=0.008)$

Pregnancy: Comparison between group A vs. group B ( $\mathrm{p}=0.270)$; Comparison between group A vs. group C $(\mathrm{p}=0.005)$; Comparison between group B vs. group $\mathrm{C}(\mathrm{p}=0.101)$

\section{DISCUSSION}

Our study was a randomized retrospective study conducted on 150 women diagnosed as PCOS by Rotterdam criteria selected from patients attending the infertility clinic of Al-Azhar Hospitals, Faculty of Medicine, Al-Azhar University according to inclusion and exclusion criteria. The patients were divided into three groups according to their body mass index: 50 patients with normal body mass index (BMI 19-24.9), 50 patients with overweight (BMI 25-29.9), and 50 patients with obesity (BMI equals or more than 30).

Obesity is a growing problem in many parts of the world. Recent estimates suggest that approximately $60 \%$ of U.S women are overweight, nearly one-third are obese and $6 \%$ are morbidly obese; also $50 \%$ of women 25-44 years old are overweight and $20 \%$ of them are obese (Makrakis, 2010).

It is by far the most common cause of hyperandrogenic anovulatory infertility and was described more than half a century ago, the underlying cause of this disorder is still uncertain (Cheng and Li, 2010).

The present study was designed to examine the relation of body mass index in PCOS patients with dose and duration of $\mathrm{HMG}$, ovulation rate and pregnancy rate. There was no statistical significant difference between three groups as regards the mean age and that there was a statistical difference between the 3 groups regarding HMG (induction days), ovulation rate and pregnancy rate, where the increase in BMI is positively correlated with HMG duration of induction BMI was inversely related to ovulation rate. Where group $\mathrm{A}$ has ovulation rate higher than group $\mathrm{B}$, and group $B$ has ovulation rate higher than group C. also BMI was inversely related to pregnancy rate where pregnancy rate was higher in group $\mathrm{A}$ than $\mathrm{B}$, and in group $\mathrm{B}$ than $\mathrm{C}$. there was no statistical significant difference between three groups as regards the mean FSH, LH, E2, PRL and TSH.

This met with the results obtained by Anjali et al. (2010) who achieved a retrospective study of medical records of women undergoing ovulation induction 
cycles where the patient were classified into three groups: normal weight $(\mathrm{BMI}<$ $\left.25 \mathrm{~kg} / \mathrm{m}^{2}\right)$, overweight (BMI >25, < $\left.30 \mathrm{~kg} / \mathrm{m}^{2}\right)$ and obese $\left(\mathrm{BMI}>30 \mathrm{~kg} / \mathrm{m}^{2}\right)$ and all of them underwent controlled ovarian hyperstimulation Ttey stated that there was no significant difference among the three study groups regarding their basal (day 2) hormonal profile including $\mathrm{FSH}$, LH, Estradiol and TSH.

In the present study, there was statistical significant difference between three groups as regards the incidence of ovulation using folliculometry. The ovulation rate was $68 \%$ in group A, $56 \%$ in group B and $28 \%$ in group C.

There were wide different ranges of ovulation rates in all the studies which may be due to the different selection criteria of patients, different initial dose and also the different number of treatment cycles.

A different outcome was obtained by Frattarelli and Kodama (2014). Patients with BMI >24 kg/m2 demonstrated a significant increase in the ovulation rate and a significant decrease in the dose and duration of gonadotrophins used another study has also reached to a reduction in fertilization rate among obese patients done by Zhang et al. (2010). These results meet those obtained by Anjali et al. (2010) and Vilarino et al. (2010).

There was statistical significant difference between three groups as regards the incidence of pregnancy using vaginal ultrasound to detect gestational sac. The pregnancy rate in group A $44 \%$, while in group B was $32 \%$, and in group C was $16 \%$.
Our results disagreed with those of Anjali et al. (2010) and Vilarino et al. (2010) as they all came out with a conclusion that there is no statistically significant difference in pregnancy rate among the different BMI groups that was studied.

On the other hand, a retrospective case control study revealed that increased BMI significantly reduces the chance of clinical pregnancy (normal weight vs. overweight: clinical pregnancy rate: $49.2 \%$, vs. $34.3 \%$ ) (Petanovski et al. 2011).

Also these results meet those obtained by Bellver et al. (2010) and Zhang et al. (2010).

Our results revealed the significant difference among the three groups as regard the dose and the duration of gonadotrophins used for ovarian stimulation. Our results showed a trend towards higher doses of the drugs used for induction in correlation to the increased BMI.

In our study, HMG duration of treatment had a mean of $10.08 \pm 2.78$ days per cycle in group A, while in group B, the mean was $12.40 \pm 2.98$ days per cycle, while in group $\mathrm{C}$, the mean was $14.44 \pm 1.32$ days per cycle. This showed a significant increase in the days of stimulation. By using the student (t-test) for equality of the means we found that there is significant difference in three groups.

Vilarino et al (2010) disagreed with our results who find out that there is no difference in gonadotrophin requirements in obese patients compared to the normal weight women during controlled ovarian stimulation. Zhang et al (2010) performed 
a retrospective analysis of 2628 cycles in Chinese couples revealed the need for higher doses of gonadotropins in obese patients.

Existing studies points to the importance of BMI as a prognostic factor for various fertility treatments. Our findings highlighted the importance of evaluating the full BMI range in relation to ovulation induction success. We found opposite effects of PCOS and BMI on indicators of ovulatory function, which was in line with current knowledge. Unlike previously conducted studies, we did not observe a significant effect of PCOS or BMI on final ART treatment outcomes.

With reference to the discussed above, the effects of obesity on ovulation induction outcome have been controversial and this may be attributed to problems with the studies done for this purpose as; the majority of them are retrospective studies, there is marked heterogeneity as regard their clinical, methodological and statistical applications: different cut-off values for BMI, different starting doses of gonadotropins, different metabolic and endocrine patterns in each woman and inability to adjust for confounders as PCOS Poor response, type of obesity (obesity can be measured using BMI or waist: hip ratio).

\section{CONCLUSION}

HMG can be given to patients with PCO (polycystic ovary syndrome) adjusting the dose according to their BMI and response with expecting satisfactory ovulation, and pregnancy rate.

\section{REFERENCES}

1. Anjali $S$, Balasubramanyam $S$, Gupta $S$ and Verma T. (2010): Effect of body mass index on in vitro fertilization outcomes in women, J Hum Reprod Sci., 3(3): 135-138.

2. Bellver J, Rodríguez-Tabernero L, Robles A, Muñoz E, Martínez F, Landeras J, García-Velasco J, Fontes J, Álvarez M, Álvarez C and Acevedo B. (2018): Polycystic ovary syndrome throughout a woman's life. Journal of Assisted Reproduction and Genetics. 35(1):25-39.

3. Cheng J and Li CY. (2010): Clinical outcomes of ovulation induction with metformin, clomiphene citrate and human menopausal gonadotrophin in polycystic ovary syndrome. J Int Med Res., 36: 12508.

4. Dağ ZÖ and Dilbaz B. (2015): Impact of obesity on infertility in women. Journal of the Turkish German Gynecological Association., 16(2):111-117.

5. Dăg ZO and Dilbaz B (2017): Impact of obesity on infertility in women,. Journal of the Turkish German Gynecological Association. 16(2):111-115.

6. Diamanti-Kandarakis E, Piperi C, Argyrakopoulou G, Spina J, Papanastasiou L, Bergiele A and Panidis D (2012): Polycystic Ovary Syndrome: The influence of environmental and genetic factors. Hormones 27,17-34.

7. Erin K. Barthelmess $H$ and Rajesh $K$. (2014): Polycystic ovary syndrome: current status and future perspective, Front Biosci (Elite Ed)., 6: 104-119.

8. Frattarelli JL and Kodama CL. (2014): Impact of body mass index on in vitro fertilization outcomes. J Assist Reprod Genet. 21, 211-215. 
9. Makrakis E. (2010): The impact of female obesity on in vitro fertilization outcomes, Journal of Minimally Invasive Gynecology, 230-237.

10.Petanovski Z, Dimitrov G, Ajdin B, Hadzi-Lega M, Sotirovska V, Matevski V, Stojkovska S, Saltirovski S, Suslevski D and Petanovska E. (2011): Impact of body mass index (BMI) and age on the outcome of the IVF process, 17:155-71.

11.Sarais V, Pagliardini L, Rebonato G, Papaleo E and Candiani M. (2016): A Comprehensive Analysis of Body Mass Index Effect on in Vitro Fertilization Outcomes Nutrients, 8(3): 109-112.

\section{Susan M, Sirmans $T$ and Kristen $A$ and} Pate Y. (2014): Epidemiology, diagnosis, and management of polycystic ovary syndrome Clin Epidemiol., 6: 1-13.
13. Vilarino FL, Bianco B, Christofolini DM and Barbosa CP. (2010): Impact of body mass index on in vitro fertilization outcomes. Rev. Bras. Gynecol. Obstet., 32: 536-540.

14.World Health Organization (2015): Obesity and overweight Fact sheet $N^{\circ}$ 311.Geneva, Switzerland: World Health Organization Lancet., 363:157-163.

15.Zhang D, Zhu Y, Gao H, Zhou B, Zhang R, Wang T, Ding G, Qu F, Huang $H$ and Lu X. (2010): Overweight and obesity negatively affect the outcomes of ovarian stimulation and in-vitro fertilization: A cohort study of 2628 Chinese women. Gynecological Endocrinology, 26: 325-32. 


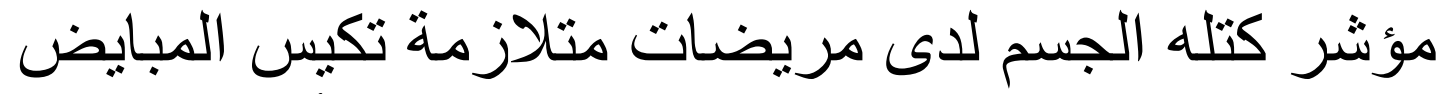 و علاقته بجر عة ومدة موجهه الغدد التناسليه الأياسية البشرية

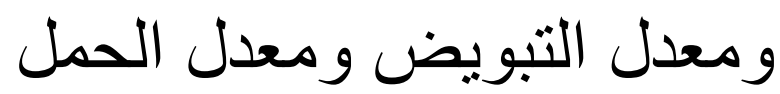

عبدالله جمال مصطقى محمد، إسماعيل طلعت الجارحى, نهى محمد صبرى قسم أمراض النساء والتوليد، كلية الطب، جامعة الأزهر

E-mail: elansaryabdo88@gmail.com

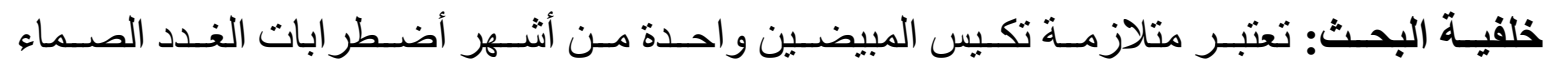

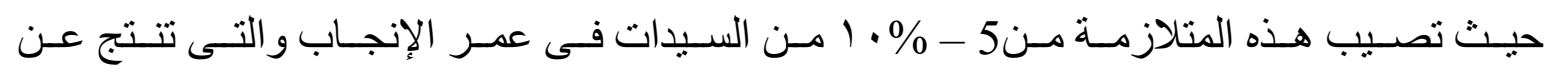

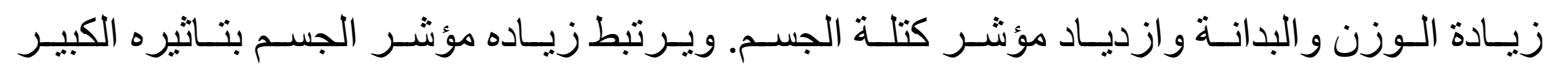

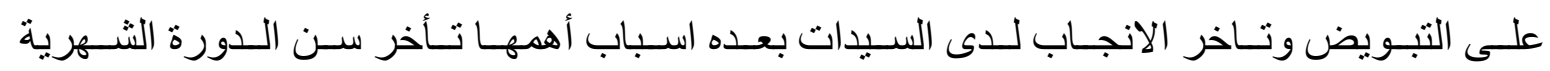

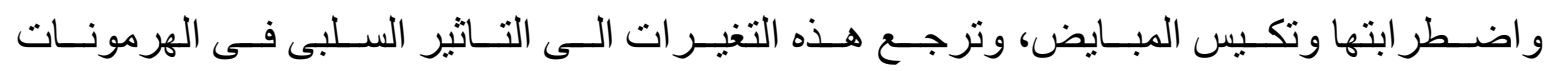
و أفر از ها وخاصة الاستروجين و الانسولين و الأندروجين.

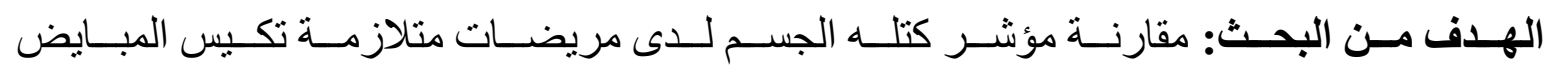

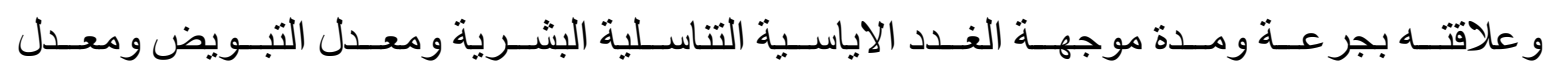

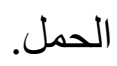

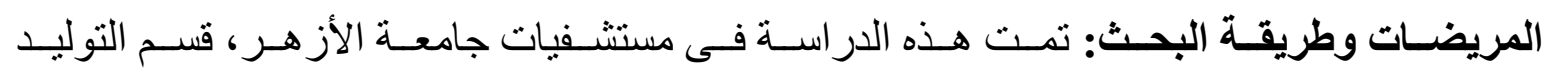

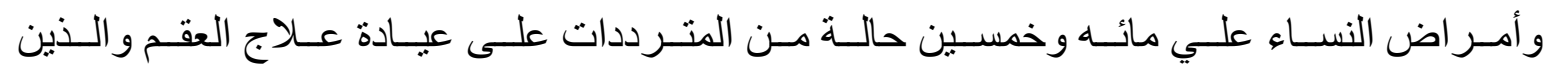
انطبقت عليهم مو اصـفات البحث وتم تقسيم الحسالات عشوائيا إلـي ثـلاث مجموعـات وذلكاتك تبعـا

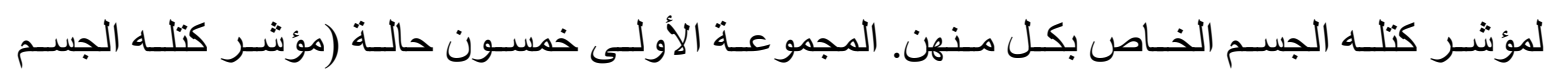

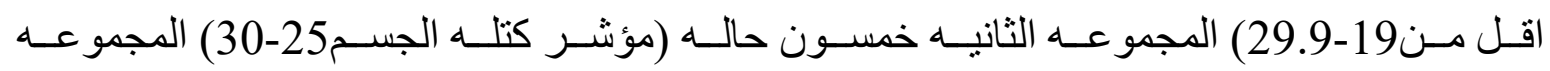

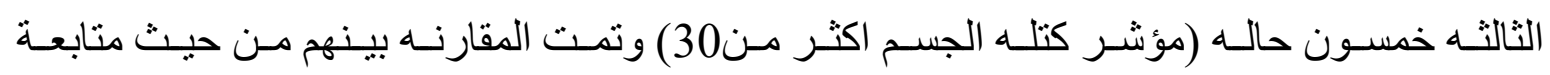

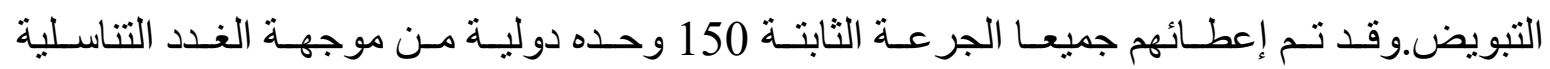

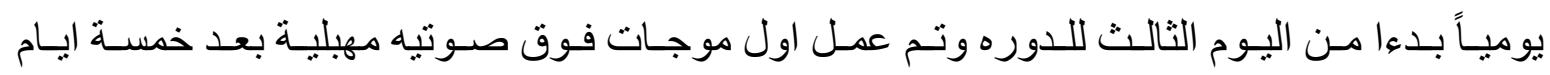
من بدء الحقن ويتم تعديل الجر عة تبعا لاستجابة المريضة. 


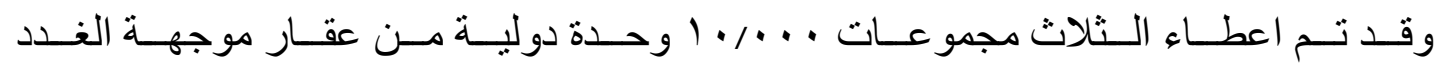

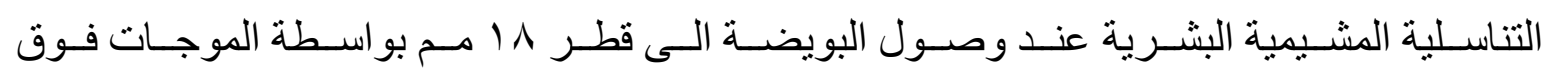

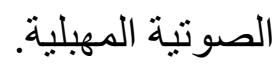

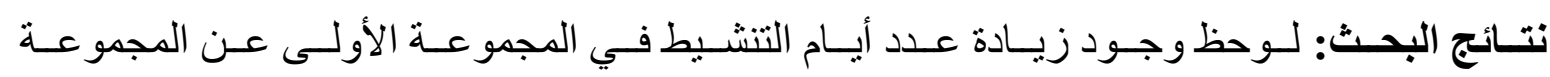

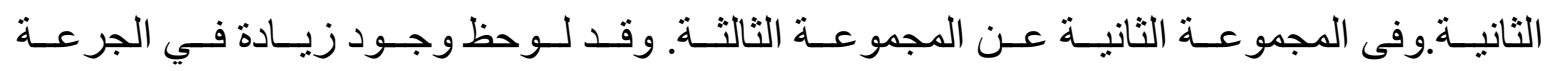

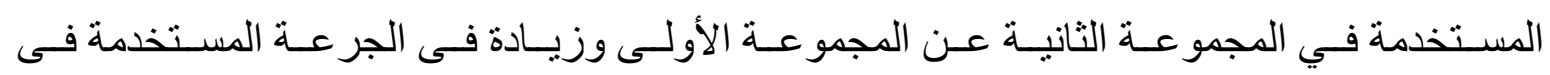

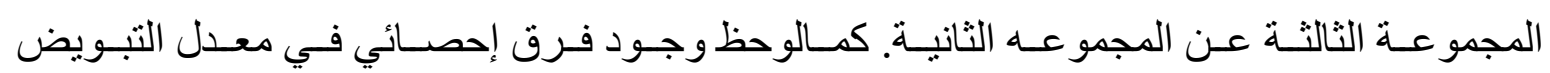

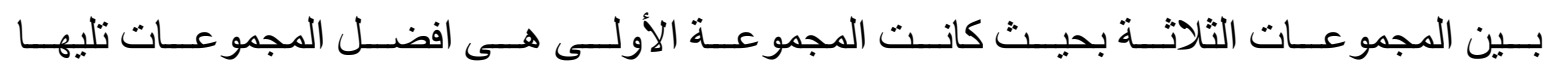

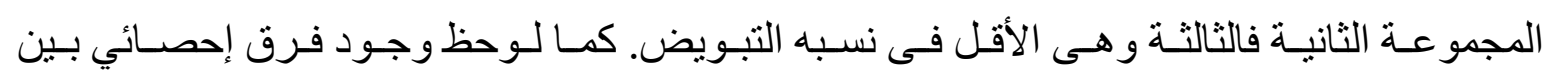

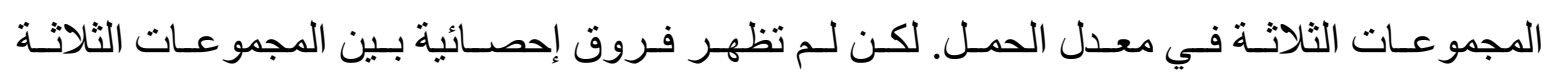

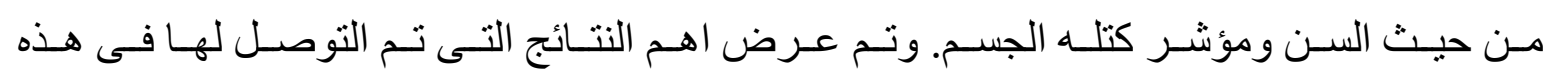

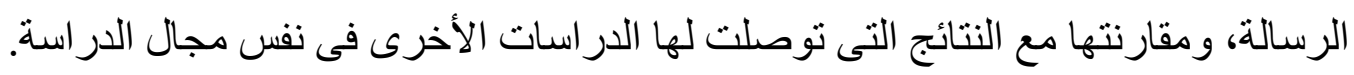

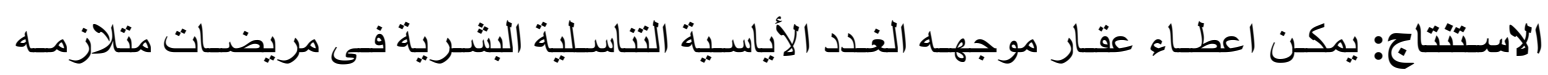

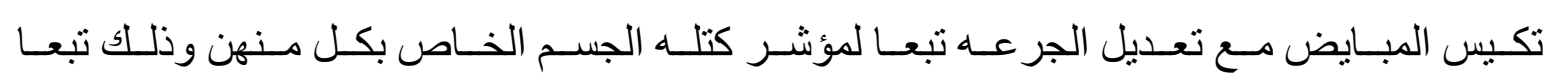

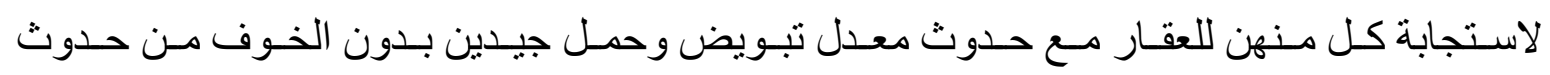

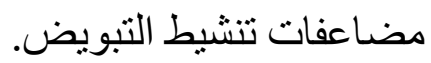

